\title{
Intonation in the Course of Solfeggio for Visually Impaired and Blind Children
}

\author{
Galima Lukina \\ State Institute for Art Studies \\ Russian State Specialized Academy of Arts \\ Moscow, Russia \\ E-mail: lukina@sias.ru
}

\begin{abstract}
The author of this article is focused on a problem of teaching solfeggio for totally unseeing and visually impaired students. The results of theoretical and practical research indicate the identity of the nature of the musical abilities of unseeing and seeing children. This gives grounds to assert that musical typhlo-pedagogics is based on general musical and pedagogical principles. However, when identifying the most important of these principles for the training and education of musicians with special needs, there is a certain shift in the semantic emphasis and correction of pedagogical methods. The author proposes the solution of specific problems of teaching solfeggio for unseeing and visually impaired, taking into account the need to develop a factor of compensation for lost vision. When the visual functions are violated or lost, the artistic potential of a person is the most conserved in relation to music, and exactly this art serves as the optimal area for the artistic development of unseeing and visually impaired students. Special attention is paid to intoning, i.e. musical activity, aimed at the integral coverage of artistic and expressive means. There are examples of intonational exercises focused on the formation and development of compensatory and motivating to creativity factors with unseeing students.
\end{abstract}

Keywords-solfeggio; inclusive art education; intonation; intoning

\section{INTRODUCTION}

Intoning is usually understood as "clear" or accurate reproduction of a pitch height, a theme or a melody with a voice or an instrument. But such a definition limits the phenomenon which also includes the meaningful content of the performed work. There is no music outside intoning. The time-honored definition by B. V. Asafiev comes to mind in this context, "...music is an art of intoned meaning" [1]

The notion of intoning is inseparably associated with the notion of intonation. "The idea, the intonation, musical forms are in constant connection: to be expressed in sound the idea becomes intonation, it is intoned" [2].

The notion of intonation is broad and complicated - it includes the interval, the popevka (melodic formula), the melodic phrase, the meaningful harmony, etc. The intonation can be vocal and instrumental, soloistic or choral. In addition, it always carries the idea and the imagery. According to the definition by V. V. Medushevsky, the intonation is "the integral unity of all the sound aspects bound with the energies of meaning", the aspects of articulation, pitch height, timbre, rhythm, volume [3]. "The sounds alive inspired with human feeling and thought, become intonations" [3].

The sound forms play the predominant role in the life of a blind child. They make up the centre of their mental process. The vibrations of timbre, intonation, and the volume can help the blind access personalities, their moods, characters, attitudes towards the people around them and their states of mind. A blind child learns how to use the sound properties of the objects, the parents' voices for orienting, recognizing and forming the images of the surrounding world.

In his short novel, "The Blind Musician", V. G Korolenko described the sound perception of the world by a blind child very vividly: "He heard the rush of spring waters, stream racing after stream, leaping among the stones, cutting their way through the soft, wet earth. He heard the beeches whispering by the windows. Their branches kept brushing together, and sometimes a twig would strike a window-pane and set it tinkling. He heard the hurried, insistent patter of a myriad falling drops, where the icicles that hung from the roof, caught by the frost at dawn, were now melting in the sun. Sharp and clear, these sounds came into the house - like round, swift pebbles, striking upon his hearing. Sometimes, too, through these nearer sounds, came the call of the cranes, floating down to earth from distant heights and fading gradually into silence, as though melting away in the clear air"1.

The children's sound perception compensates the blindness and visual impairment. This is how Denis Diderot described his impression of communicating with a blind person in his "Letter on the Blind": "His memory of sound is strikingly developed; faces are less various for us than voices are for him. He can distinguish an infinite number of voice tones imperceptible for us because they are not so interesting for us as they are for the blind... Somebody had an idea to ask our blind man if he would be happy to have eyes. "Unless I was so overcome with curiosity," he answered, "I'd rather have long arms... That's why it would be better

Translated by Helen Altschuler, The Blind Musician. Progress Publishers, Moscow, 1978, pp. 9-10. 
to improve the organ I have than to provide me with the missing one"".

Which 'organs' of a blind child can be improved at solfeggio classes? The organs of hearing and phonation, those that are parts of "the systemic 'organ' of musical pitch perception" [4]. Any musical activity is provided with coordinated functioning of acoustic and vocal-motor organs. But it is intoning that develops their coordination, because intoning only can enable their most accurate cooperation.

In his book "Specific character of articulation and techniques used in intoning by visually impaired bayanists and accordionists", M. I. Imkhanitsky points out that "very often we happen to hear musicians of all kinds of musical background playing inexpressively and impersonally, particularly, those with eyesight defects, including the people who have reached highest recognition levels. <.. > It turned out that neither an artist's expressiveness nor their technical virtuosity or violent temper can prevent indistinct articulation. What are the causes of the paradox? One of the most essential ones is neglecting the laws of intoning and musical articulation" [5].

The direct connection of intoning and the so-called inner hearing was recorded by Yu. N. Tyulin in the 1930's. B. M. Teplov wrote about it in the 1940's: "Musical conceptions are very closely connected with vocal movements, with 'inner singing', just like speech acoustic conceptions are extremely closely linked with speech movements" [6].

Solfeggio classes are intended to concentrate on different forms of intoning as the foundation of developing an ear for music, artistic taste and memory of a blind child. It should be taken into consideration that in teaching practice visual perception has to be replaced with tactile and kinetic, musical and acoustic conceptions as well as with impressional and emotional experiences. These three psychophysical functions compensate the privation of eyesight and ensure the positive result of elementary education.

\section{THE WORK OVER INTONATION AS A FORM OF}

DEVELOPING THE MAIN ELEMENTS OF THE SYSTEM OF FORMING AND DEVELOPING THE COMPENSATORY FACTORS

\section{A. Developing Interest and Artistic Taste}

Interest is the most important motivating factor in the process of forming a blind person's musical and acoustic concepts. The interest is born only after an emotional reaction to the beauty of a musical work. A child's sensitive nature, regardless of his/her physical abilities, can respond to the poetic images of beautiful melodies. That is why, besides standard thematic exercises or nursery songs, it is important to turn to high music samples at solfeggio classes - melodies by Bach, Mozart, Glinka, Tchaikovsky, Prokofiev etc., which are easy to intone.

Verbal characteristics of music, collective reflection on the character of music are important in developing the interest. Listening to the piece planned for learning provokes active interest and develops artistic taste. It will not take much time but listening to a professional performance will be the child's lasting impression.

Vivid art impressions make up the strongest impulse for developing blind people's interest for music. The sounds' beauty, catchy melodies, unusual consonances involve a child into the sphere that little by little becomes easier to access.

One of junior children's specific characteristics is their inability to concentrate on the same thing for a long time. As K. D. Ushinsky pointed out, "the younger a child, the less able he is to be permanently active in one and the same field". It is true for blind children, too. K. D. Ushinsky also gave the following teaching recommendations: "Changing activities affects a child much better than complete relaxation"; "The more varied your class and the activities you want the children to do, the more you will manage to do". Considering this, a teacher should vary the forms of presenting the materials to visually impaired children at solfeggio lessons. The methods of musical illustration, tactile and kinetic demonstration, formative movements, re-intoning and developing creativity, numerous repetitions, descriptive characteristics and collective work can help make a solfeggio class creative.

\section{B. Developing Attention}

Didactics defines attention as one of the main personal characteristics; it is a psychological factor of any successful meaningful activity.

Attention plays the regulating role in blind musicians' understanding a musical piece. It is a compensatory factor based on acoustic perception and tactile sensations. Attention is formed with developing the skills connected with reception of the sounding musical material and understanding its intonation content.

Here is a set of exercises that help students concentrate their efforts on a certain educational technique.

- Ensemble singing of quint (or octave) range scale with one student singing stable degrees loudly, while all together sing unstable degrees quietly.

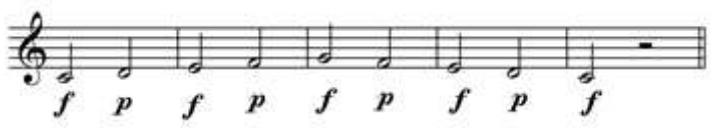

- Singing of quint (or octave) range scale with stable degrees sung aloud while unstable ones are sung mentally.

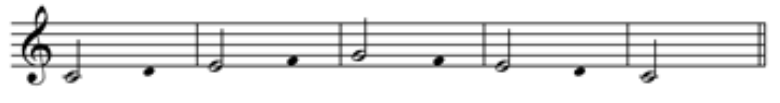

Doing this exercise, it is extremely important to get the students to be active in listening to the mentally intoned tones, to intone them instead of omitting mechanically.

- Listening to Pas de deux (Andante maestoso) from "The Nutcracker" by P. I. Tchaikovsky and 
remembering the basic melodic motion of the main theme. Before that, tuning in $\mathrm{G}$ major.

- Intoning of the drone tone. It is useful to sing it in various dynamic arrangements, as well as in different types of harmonization.

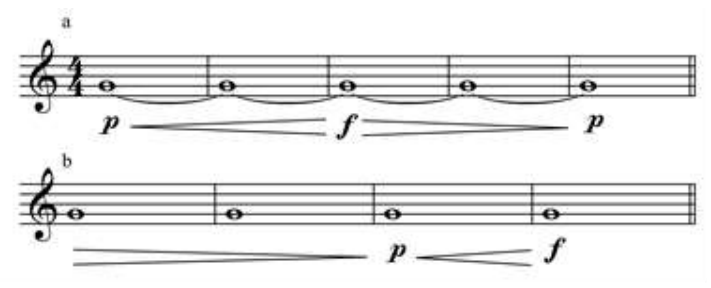

- Singing melodies in the predetermined rhythm as far as the keynote, with preserving or changing its image content.

- Singing scales in parallel keys in turns and by two voices.

- Completing phrases (question - answer) to a thought or a period. This exercise is aimed at developing both concentration and creativity.

- Transposition of a learned melody with some variation elements.

- Game exercises aimed at concentration. For example, there is such a game for junior classes: some students sing the tune of the Russian nursery song "Akh ty, kotenka-kotok" (Oh you pussy-cat) with G ostinato pattern, the teacher accompanying; the others take care not to let the tune "leave" the note G.

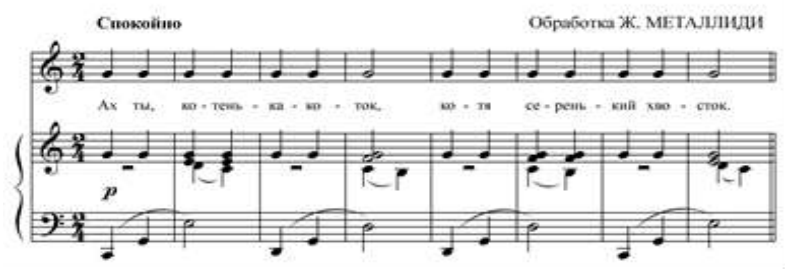

- Exercises aimed at just intonation at one tone. Having listened to the tuning chord played on the piano $^{2}$, single out the upper tone (or the bass) and intone it extendedly pronouncing any vowel sound. If the tuning chord is consonant, the voice sounds calm and concentrated; if it dissonant, the voice is a little stressed and excited [7].

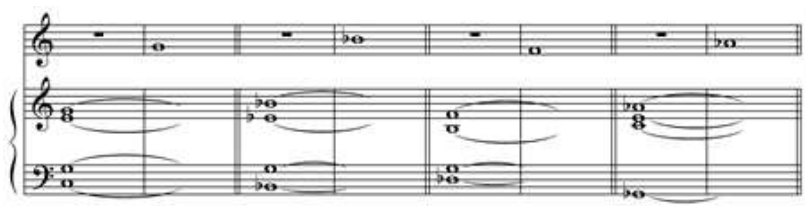

2 The tuning chord is a tuning support. It reveals the tonal meaning of tuning and is a strong support for the ear facilitating intoning.

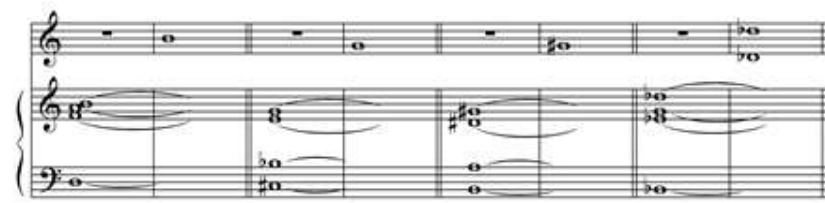

Practicing such exercises involves mental presentation of the perfect unison interval from the upper of lower tone of the tuning chord and long voiced repetition of the tone.

- Having attentively listened to a dissonant chord, single out the upper tone and intone it at the required syllable continuously. At the harmony change, it is necessary to make the voice sound a little lighter or darker.

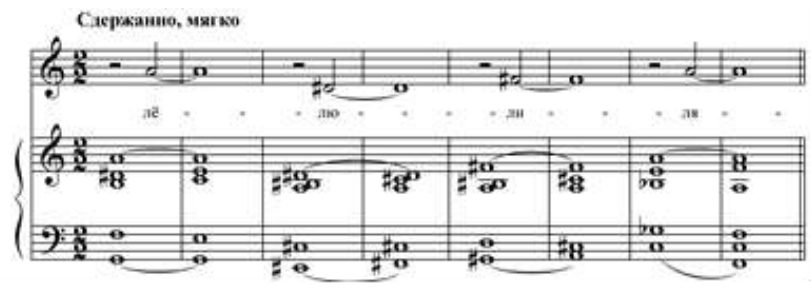

Just one-tone intonation is a guarantee of overcoming many vocal and audial difficulties as well as performing problems in a special instrument class. If a young musician feels the beauty of sound duration, he/she will succeed in performing the most difficult technique of playing smoothly, legato. As an inspiring sample, we can offer Bach's Aria from Orchestral Suite No. 3 in D major.

\section{Developing Audial and Kinetic Connections}

Audial and kinetic connections as a compensatory form of the lost eyesight are developed in the first period of blind musicians' education and made up of sensations and conceptions. Teachers of instrument thoroughly think of the game activities related to compensatory functions. They are the activities formed in the process of simultaneous audial impression of music and remembering the hand movements with tactile sensations. Preliminary representation of the game activities helps a student dispose of unnecessary movements, relieves the unwanted muscle strain, and encourages freedom. In solfeggio classes, the ability to work over intonation exercises with the help of audial and kinetic representations makes learning process more effective.

1) Intonation exercises connected with physical actions:

- Singing of a scale naming the degrees and showing a corresponding number of fingers: one index finger means the first degree, two fingers (the index and the middle ones) mean the second degree and so on.

- Singing of an ascendant or descendant scale with the corresponding hand movement.

- Singing of a scale with waving hands in accordance with different time signatures.

- Exercises including rhythmic movements: gestures of different kinds, clapping, knocking etc. For example, beating the ostinato rhythmic pattern with a hand or a 
pencil during tune singing. Another useful exercise is presenting a rhythm contrast to the performed melody.
- Chanting with naming the degrees and showing the number of fingers corresponding to the degree. For example:

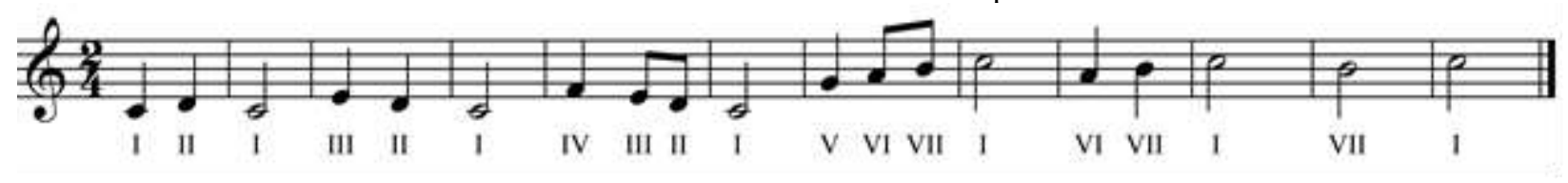

Singing this with gestures is aimed at developing blind children's modal hearing; besides, it is a kind of alternative to "The Ladder" or Bulgarian Stolbitsa. By and by, a child remembers the connection between the name of the degree with its sound and the gesture showing it. This connection is established and then used in different forms of work, such as auditory analysis, dictation and practicing solfeggio.

\section{Developing Musical Memory}

As any activity, intoning is based on memory. In the process of intoning a musician 'plunges' into the 'storehouses of memory' and takes out the necessary tones, mode degrees, intervals, and melody patterns.

Musical memory is a musician's ability to remember, understand, keep and reproduce musical information. This ability is a compensatory factor for blind musicians, and it has its own specific character. Absence of visual analyzer makes a student think twice and concentrate on the learning action itself; it also gives them an opportunity for analysis, better listening, and keener feeling.

Musical memory progresses when a student understands the logical structure of a melody, remembers the sequence of actions while performing, can connect the antecedent with the precedent, actively employs the process of perception, audial representations connected with associative thinking, rational constructs etc. Activated "skills and cooperation of more or less clear musical conceptions with the vocal apparatus activity ... allow to perceive and reproduce musical elements as conscious and meaningful intonations practically simultaneously and automatically" [8].

The ability to quickly remember and keep the musical material in memory is a compensatory factor for blind musicians. Blind people's memory is less selective than that of seeing people (because it cannot use visual images), nevertheless blindness activates the interconnection of audial and emotional perception, originates associations, promotes image thinking, and accelerates information processing.

In addition, developing logical memory raises the work efficiency because it takes less time to remember the musical material due to elaborately planned classes. K. A. Martinsen calls this type of studying and remembering a musical piece "constructive memory".

1) Intonation exercises aimed at developing musical memory:

a) Exercises for audial analysis or oral dictations: Imagine the played extract as a sequence of mode degrees; sing it naming the degrees and then the notes. The exercises are given in the keys comfortable for the voice. The most appropriate material for practicing audial analysis is a rhythmically structured scale.
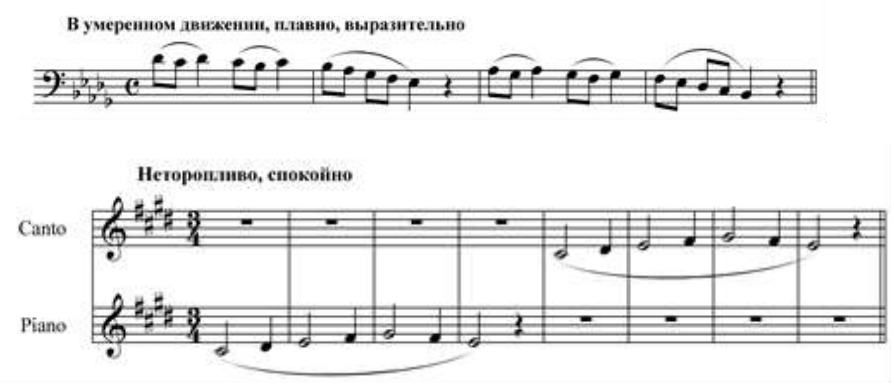

The main objective of such exercises is to consolidate mental representations of melody and rhythm as well as to activate musical and rhythmical memory.

- Analyzing melody elements by ear with its further singing.

- Singing of a round.

- Improvising melodies on a given theme.

- Learning classical melodies by heart.

\section{E. Developing Inner Ear for Music}

R. Schumann wrote in his "Life Rules": "Ear training is the main thing... You must develop yourself so that you could understand music...". In this context, ear for music is a special type of hearing; after a shrewd remark by E. V. Nazaikinsky, it can hear music "in three ears at once, one of which is a tactile ear, the second one is an emotional ear, and the third one is a thinking ear" [9].

Ear for music is a specific instrument of cognitive activity for a blind child.

\section{So, what is inner ear for music?}

Inner ear for music is "an ability to mentally represent the tones and their relations without an instrument or a voice" (the definition by N. A. Rimsky-Korsakov). Modern musicology offers a broader definition of inner ear as an ability "to mentally, inwardly represent and experience the sounds and sound images based on former impressions assisted with memory and imagination" (A. L. Ostrovsky). This ability encourages silent singing, mental listening to music or another musical activity. Thus, "a musician's inner audial images are not only a psychological instrument of composing or performing music but also a very important channel of autocommunication, understanding and control of one's own inner musical life" (M. S. Starcheus) [10]. 
It is known that a non-professional eye perceiving a compound color does not distinguish its components. Mostly, a student's ear perceives the sound colors as a whole, too. But unlike eyesight, even non-professional ear can distinguish the compound sounding both as a whole and separately distinguishing the consonant tones. For example, in accordance with the objective and psychological disposition, an ear can single out a part in polyphony; it distinguishes different consonances of the tonic or dominant. With regard to solfeggio, the ear is a method of hearing and understanding the processing musical speech.

V. N. Kulakov emphasizes that it is impossible to speak about inner ear as a compensatory factor for a blind musician if the processes of compensation have not been formed in connection with establishing attention, perfecting audial and kinetic links, evoking interest in musical practice, and developing musical memory. There is compensation only when a performer mentally transforms the intended sounding into performing actions that are necessary for representing a musical piece [11]. Accordingly, a solfeggio teacher should remember that inward intoning is an active factor of the audial understanding besides inner ear.

At solfeggio lesson, such methods as musical illustration, tactile and kinetic demonstration, forming movements, reintoning and developing creativity, multiple repetition, verbal characteristics and collective creative work promote musical and audial representations and activate ear development.

1) Intonation exercises aimed at inner ear development:

- Successive alternation of singing aloud and silently.

- Alternate singing of a scale by two groups or two students; successive singing of stable and unstable degrees of the mode.

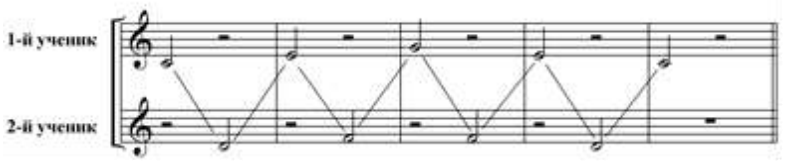

- Intonation and audial exercises with tuning accompaniment:

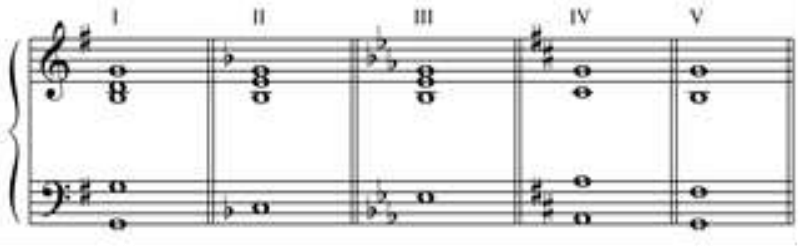

Analyze each chord defining the key and intone the upper sound.

Besides inner ear, this exercise is aimed at practicing perception of mode changes. Thanks to chord tuning, several keys are in work at the same time. As soon as the chord changes, the $\mathrm{G}$ sound gets a new degree parameter.

- Exercises with chant singing and naming the degrees ("one-two-one", "three-two-one" etc.).
- Standard tonal chants with the tuning chord $^{3}$ :

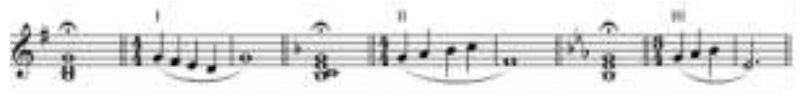

The chord activates hearing and facilitates finding the first sound. Each chant should be analysed beforehand.

The chant learned consciously will emerge in a student's audial mind without failure any necessary moment (including the work over a dictation).

\section{F. Developing Conscious and Expressive Intoning}

The art of performing music excludes emotionless reading the notes even within the most confined limits. The practical concern of both special instrument classes and solfeggio lessons is keen attention to expressiveness, to all the aspects including phrasing, dynamics, tempo and coloristic peculiarities.

One of the intoning methods attractive for students is vocalizing; its active employment helps remember a relatively complete melody with audial perception and express it with the voice. The focus is the singing process and practicing accuracy and musicality.

1) Intonation exercises:

Completing the motives played by the teacher so that turning will be the result.

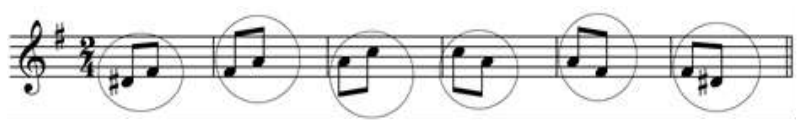

Sing the whole chain of tunes aloud, then sing one bar silently and another one aloud.

After revision sing in turns in different moods courageously, timidly, gloomily, impulsively, joyfully.

Chants in minor key:

- Quarter notes - lyrically, half notes with dots energetically:

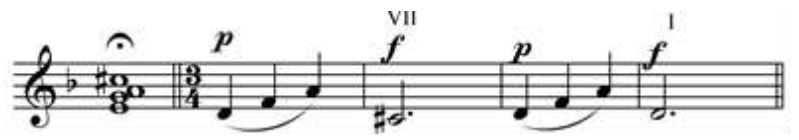

- Each double measure with the same mood: now with $p$ dynamics, dying away, now with $m f$ dynamics, gravely:

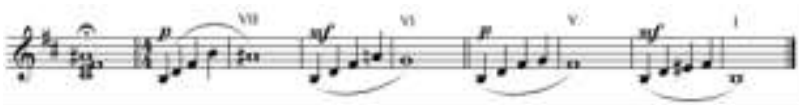

- Improvising melodies based on chanting chords with a simple metric and rhythmic pattern. The first phrase is a kind of reference point, the second one has similar harmony:

\footnotetext{
${ }^{3}$ Tonal chants are "short easily sung elements of the modal scale, reflecting in a concentrated form the system of links and tensions between the mode degrees" (Maksimov S. E. Solfeggio for the vocalists - M., 1984, p. 13).
} 


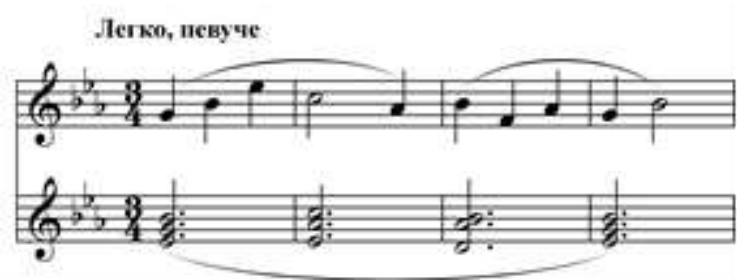

Teaching improvisation uses a supporting harmonious sequence played on the piano in the classical form of an eight-bar period. This kind of work encourages artistic imagination.

- Improvisation backed with harmony that is more complex. The teacher suggests forming a student's own melody as a short improvisation completed with the tonic chord.

- Expressive solo or ensemble playing the learned classical melodies at the end of the class.

\section{CONCLUSION}

If visual functions are impaired or disordered, individual artistic resources are mostly unharmed in the sphere of music, and this is the kind of art which is the best possible variant of developing artistic abilities of blind and visually impaired people.

The author's methodology of teaching solfeggio is grounded on such important mechanisms of compensating blindness as musical and audial representations, singing, tactile and kinetic sensations, and memory, which makes the process of teaching visually impaired children more comprehensible and efficient [12]. It is also important to have creative contact of the teacher and students, which is based on mutual understanding and cooperation.

The process of teaching solfeggio to blind children is presented as a balance between specific difficulties and some advantages of working with the blind. Thus, inability to read music prima vista is compensated with developed memory, lack of visual perception gives the students an opportunity to concentrate on their own audial impressions. According to L. S. Vygotsky, correcting and compensating a defect is searching new "side roads of progress".

Since ancient times people have noticed that the organism functions rearrange after losing an organ, for example hearing becomes keener instead of lacking vision, memory becomes more active, too. Compensation can be defined as a universal ability of an organism to replace disorders or lacking functions in this or that way. To put it simply, man's nature is organized in such a way that any missing ability is sure to be compensated with others.

Practical experience with adult blind musicians including the students of Russian State Specialised Academy of Arts (Moscow) demonstrated a certain result of perfecting their potential. Besides the students' musical abilities, teachers observe their perfect memory, their striking attention, their ability to concentrate "right here, right now", their analytical thinking, open-mindedness, their amazingly sensitive tactile perception, their particular responsibility. These qualities are a kind of objective for a teacher working with blind children. To achieve the result the most efficient work is that with intonation, or intoning, understood not only as accurate sound reproduction, but also within the whole range of musical expressive means.

\section{REFERENCES}

[1] B. V. Asafiev, Musical form as a process. L., 1963, p. 344.

[2] B. V. Asafiev, Intonation. M.-L., 1947. P. 153.

[3] V. V. Medushevsky. Intonation for of music. M., 1993, p. 4.

[4] A.N. Malyukov, Emotional aspect of schoolchildren's musical development // Development tendencies of regional systems of general and professional musical education. Materials of the 4th AllRussia research/practice conference. Saransk, 2003.

[5] M. I. Imkhanitsky, Articulation and technique characteristics in intoning by visually impaired bayanists and accordionists. M., 2016.

[6] B. Teplov, Psychology of musical abilities. M., 1947, p. 248.

[7] This exercise as well as the next one are offered by S. E. Maksimov in his manual. See Maksimov S. E. Solfeggio for vocalists. M., 1984. The objective of the exercise is "to prepare the ear to service" (p. 216)

[8] B. Nezvanov. Intonation in the course of solfeggio. - L., 1985, p.12.

[9] M. S. Nazaikinsky, On psychology of musical perception, M., 1972, p. 27.

[10] M. S. Starcheus, Musical ear. M., 2003. P. 10.

[11] B. N. Kulakov, Formation of compensatory factors in blind musicians as a condition for optimizing the educational process (on the basis of work with blind bayanists, accordionists). Abstract of Cand.Sc. dissertation paper (Pedagogics). M., 2000.

[12] Lukina G. U., Lisovoi V. I. Methodology of teaching solfeggio for visually impaired and blind children in children's music school: Scientific and methodical manual. M., 2017. 